


Sea ice in the Arctic is more variable and mobile than it was 30 years ago, causing problems for shipping.

\title{
Arctic sea ice needs better forecasts
}

\author{
Foster partnerships and share data to reduce hazards in \\ fast-changing northern waters, says Hajo Eicken.
}

A $s$ the Arctic sea ice begins to retreat this summer, fleets of ships and drilling platforms are poised to enter the newly open waters. Each year, more of the region is accessible for longer. The seas freeze in the autumn several weeks later now than they did three decades ago ${ }^{1}$. The Arctic ice pack is on the verge of becoming seasonal.

Fast-changing sea ice brings hazards. Last summer, exploratory oil drilling in the Chukchi Sea off Alaska was halted on the second day when an incursion of ice threatened the safety of personnel and vessels. Such events will become more common as Arctic maritime activity grows and as the sea ice gets more variable and mobile ${ }^{2}$. With the area of permanent ice shrinking, social and environmental pressures will rise as people and animals compete for access ${ }^{3}$.

Urgent action is needed to track changing conditions in the Arctic. Governments, agencies, indigenous peoples and the private sector all recognize the urgency and are engaged in a range of monitoring observations aimed at adaptation and mitigation. But, despite the partnerships that were built during the International Polar Year in 2007-08, current efforts are patchy.

What is needed are joint data-management policies and integrated observation planning. That is what was agreed at the first Arctic Observing Summit - a meeting of Arctic stakeholders held earlier this month in Vancouver, Canada, to discuss better coordination of and collaboration 
$>$ for collecting and disseminating information. The question now is: what practical steps are needed to make this network real?

The scale of challenges in the Arctic requires more than simply moving existing approaches to the top of the world. New 'communities of practice' must be fostered alongside tools and support structures that aid information sharing and interpretation for different users.

\section{FICKLE FLOES}

Mapping sea ice is technically challenging. In summer, pools of meltwater on the ice surface confuse the microwave satellites that track sea ice so that they record the wrong ice concentrations. Newly formed ice contrasts little with open water and can be mistaken for waves or foam. My collaborator Winton Weyapuk - an ice expert and hunter who is a member of the Inupiaq people from northern Alaska typically reports ice forming in coastal waters days before satellites detect it. This discrepancy, caused in part by the low resolution of satellite images, could be calamitous for maritime users.

Predictions of melting, freezing and movements of sea ice are difficult in a rapidly changing Arctic. Most of the data informing predictive models were derived for thick, old ice, which dominated the ice pack until a few years ago. We know little about the physical processes that govern the current mix of young (first year) and old ice.

For instance, the seasonal melt of young ice, which absorbs more solar heat and is more mobile than old ice, has proven challenging to predict. It is known to influence Earth's climate, atmosphere and ocean system, but the precise natures of atmospheric feedbacks, ocean circulation and heat retention are only now emerging and are difficult to model ${ }^{4}$. The Arctic ice pack also responds rapidly to weather and currents ${ }^{2}$. Long-term forecasting of sea-ice retreat is thus inherently limited.

Differing terminology and perspectives can be a problem. This was brought home to me last year at a workshop on sea-ice descriptions in Anchorage, Alaska, organized by the Exchange for Local Observations and Knowledge in the Arctic. Geophysicists, ice experts from indigenous communities, maritime operators and agency personnel came together for two days to share information about the seasonal ice cycle. We examined photographs, drew conceptual maps and reviewed scientific and local words for various types of sea ice.

It soon became clear that many terms are easily confused. The stages of 'new ice' that are considered hazardous by regulators, safe to walk on by the Inupiaq people, detectable through remote sensing or capable of

damaging coastal structures vary by days. Observations and predictions of sea ice therefore must be tailored to users.

Shortage of data is not always a problem. For example, around half of the 45 marineobservation programmes on the US side of the Chukchi and Beaufort Seas produce sea-ice information or relevant oceanographic data, with some programmes yielding up to 20 data sets each. But many data sets are difficult to find and access, and do not include products of immediate use to people in the Arctic. The data producers are mixed: one-third is based in academia, onethird is overseen by government agencies, one-fifth is operated by industry and the remainder are from countries other than the United States.

There is no single access point for Arctic data. Establishing one may not be neces-

\section{"Combine}

sensor

networks

with boots on

the ice and

boats in the

water." sary, as long as interoperability and open exchange between repositories can meet many users' needs. But common priorities for Arctic monitoring still need to be developed, including a set of primary sea-ice variables that should be tracked as a minimum requirement.

A consensus is emerging among researchers that the data should at least include icethickness measurements from satellites and airborne surveys; records of ice-surface and ice-bottom melt; information from drifting sensors on the evolution of ice properties; and the quantification of late-summer ocean heat using autonomous sensors and remote sensing $^{5-7}$. Studies of interactions between the ocean, sea ice and the atmosphere at drifting ice stations will help to improve our understanding of these drivers and changes while unravelling the importance of such processes for marine ecosystems.

Observing strategies need to be aligned and streamlined. Existing efforts can help - such as the Arctic Council's initiative to catalogue various observing activities (called Sustaining Arctic Observing Networks, or SAON) and the Global Earth Observation System of Systems (GEOSS). But a broader approach to data gathering and dissemination is needed so that social and ecosystem impacts can also be addressed.

Translating the needs of Arctic users into scientifically tractable questions can be a first step toward broadening collaborations. The Arctic Sea Ice Outlook ${ }^{5}$, a compilation of seasonal projections for the minimum extent of Arctic sea ice, for example, is moving beyond its academic origins to develop tools that are useful to governments, companies and the public. Last year, for instance, near-real-time estimates of ice thickness improved predictions of lingering sea ice in the North American Arctic ${ }^{8}$.

It is crucial to sustain observations and data sharing for the long term. International coordination of funding to maintain vital observing programmes is lacking, however, despite its importance for maritime safety in the Arctic.

\section{ARCTIC CROSSROADS}

New partnerships and processes are needed to track and predict sea ice. National weather and ice services and the World Meteorological Organization (WMO), based in Geneva, Switzerland, have a track record and should play an important part. But the impetus has to come from a broader base, including all Arctic stakeholders. The following steps are needed.

First, the priorities of Arctic scientists and other users must be defined for seaice observation, prediction variables and regions of interest. These must ensure safe maritime operations and protect ecosystem services and habitats. Observations and predictions should target ice-associated hazards, such as the remnants of old, thick ice or highly dynamic regions, as well as services that the ice provides, such as a platform for marine mammals and people.

The standard products released by ice and weather services will not fit this bill. Users must identify which aspects of the ice are most important to them. It may be the distribution of rotten, sparse ice that supports colonies of walruses and seals during the late spring, or the degrees of ice morphology, roughness and thickness that allow people safe passage across it.

Second, studies of ice processes must be carried out in a much more dynamic, meltwater-dominated Arctic Ocean environment. In the past, perennial ice served as an ideal platform for drifting sensors and field camps. The transition to seasonal ice requires amphibious drifters and autonomous airborne or submarine vehicles to do the same tasks.

Sea-ice models and remote-sensing algorithms will have to consider the decay of seasonal ice through the summer. Interdisciplinary field campaigns that combine sensor networks with boots on the ice and boats in the water can explain how the pulse of seasonal meltwater affects ice properties, mechanics and related ecosystems as well as threats to offshore structures.

Third, to translate these priorities into viable programmes we need a forum to link experts from different stakeholder groups ${ }^{3}$. Governments and agencies, industry and private foundations should provide sustained funding to put efforts such as the Arctic Observing Summit on a solid foundation, administered by SAON and the International Arctic Scientific Committee.

Pressing next steps include the adoption 
of a policy that promotes rapid, open access to observing data, following the protocols developed in the International Polar Year'. Frameworks for helping to plan and coordinate long-term observing activities across the scientific community and other sectors need to be established.

The community-based observing networks from the International Polar Year, which focus on variables related to local environmental threats or benefits, are a good start. But to be accessible to others, these data should be entered into wider networks such as those of the WMO. Similar to the practice of joint resource management ${ }^{10}$, the scientific community, stakeholders and decision-makers all need to be included in governance from the outset to help ensure relevance and efficiency.

Opportunities remain for the private sector to contribute to such collaborative networks. Offering up commercial vessels or infrastructure as platforms for scientific observations, sharing data and engaging the research community in the planning stages of industry observing programmes would go a long way towards establishing a 'network of networks'

Last month, I was fortunate to be out in a small boat off Toksook Bay in Alaska with ice experts and hunters from the Yup'ik people. We were surrounded by jagged, fast-moving chunks of ice that, to me, seemed hostile. To my companions, it was all in a day's work. I recalled a sentiment I had heard from a marine-mammal expert in Barrow, more than 1,000 kilometres farther north, where the ice is now unstable. He stated that the key to adapting to increasingly dynamic ice is to learn from those to the south, such as in Toksook Bay. The charge to the scientific community is to help to create a foundation for such mutual learning to occur.

Hajo Eicken is professor of geophysics at the University of Alaska Fairbanks, Fairbanks, Alaska 99775, USA.

e-mail:hajo.eicken@gi.alaska.edu

1. Markus, T., Stroeve, J. C. \& Miller, J. J. Geophys. Res. Oceans 114, C12024 (2009)

2. Rampal, P., Weiss, J. \& Marsan, D. J. Geophys. Res. Oceans 114, C05013 (2009).

3. Lovecraft, A. L., Meek, C. \& Eicken, H. Polar Geogr. 36, 105-125 (2013)

4. Screen, J. A. \& Simmonds, I. Nature 464 , 1334-1337 (2010).

5. Calder, J., Eicken, H. \& Overland, J. in Understanding Earth's Polar Challenges: International Polar Year 2007-2008 - Summary by the IPY Joint Committee (eds Krupnik, l. et al.) 405-410 (CCl Press, 2011)

6. National Research Council. Seasonal to Decadal Predictions of Arctic Sea Ice: Challenges and Strategies (National Academies Press, 2012).

7. Kauker, F. et al. Geophys. Res. Lett. 36, L03707 (2009).

8. Lindsay, R. et al. Geophys. Res. Lett. 39, L21502 (2012).

9. Parsons, M. A. Nature 458, 830 (2009).

10.Berkes, F. J. Environm. Mgmt. 90, 1692-1702 (2009).

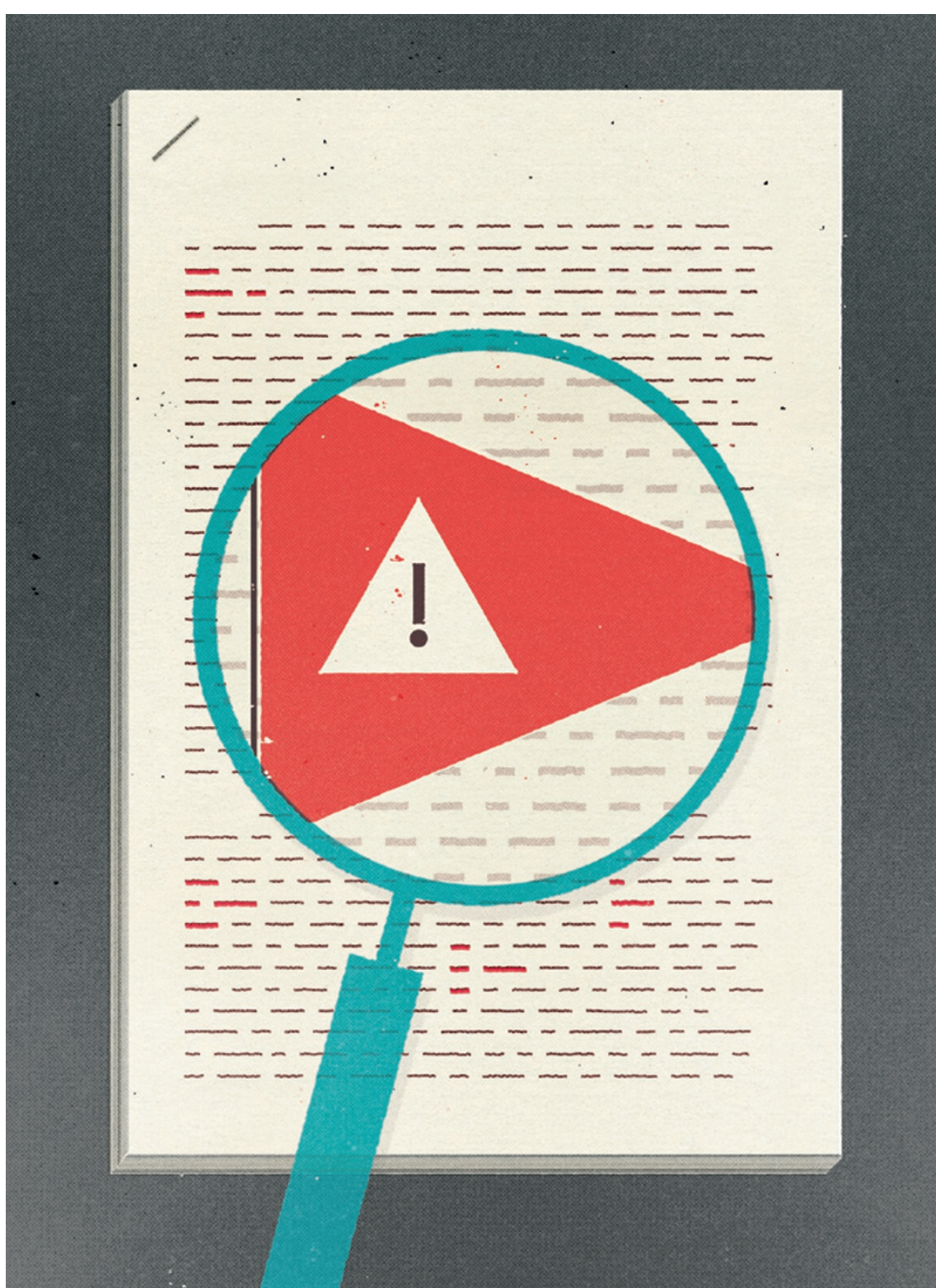

\section{Six red flags for suspect work}

\section{Glenn Begley explains how to recognize the} preclinical papers in which the data won't stand up.

A few months ago, I received a desperate e-mail from a postdoctoral scientist. Researchers including me and my colleagues - had just reported that the majority of preclinical cancer papers in top-tier journals could not be reproduced, even by the investigators themselves ${ }^{1,2}$. The postdoc pleaded with me to identify those papers, saying: "I could be wasting my time working on that project." This was true, but we had signed confidentiality agreements that prevented us from revealing the specific papers. Furthermore, identifying them would not address the broader, systemic issues in research and publishing that create a plethora of papers that don't stand up to scrutiny.

There were some glaring differences 